\title{
Avós Guardiões: Uma Revisão Sistemática de Literatura do Período de 2004 a 2014
}

\author{
Maria Teresa Barros Falcão Coelho ${ }^{1}$ \\ Faculdade Pernambucana de Saúde \\ Cristina Maria de Souza Brito Dias \\ Universidade Católica de Pernambuco
}

\begin{abstract}
RESUMO - Os avós guardiões são responsáveis pelo cuidado e criação integral dos netos. Foi realizada uma revisão sistemática de literatura nas bases de dados PsycINFO (APA), Scielo e Lillacs com o objetivo de analisar artigos científicos sobre os avós guardiões publicados no período dos últimos dez anos (2004/2014). De acordo com os critérios de inclusão e exclusão, 11 artigos foram selecionados para análise. Constatou-se que os artigos indexados na base Lillacs são predominantemente descritivos e os indexados na PsycINFO (APA) são, na sua maioria, voltados para a discussão de propostas de intervenção junto às famílias dos avós guardiões e seus netos.
\end{abstract}

Palavras-Chave: avós, família, relações familiares, práticas de criação infantil, comportamento de cuidado da criança

\section{Guardian Grandparents: A Systematic Literature Review Between 2004 to 2014}

\begin{abstract}
Guardian grandparents are responsible for the care and upbringing of their grandchildren. It was performed a systematic literature review in the databases PsycINFO (APA), Scielo and Lillacs with the aim of analyzing scientific articles on guardian grandparents published during the last ten years (2004/2014). According to the inclusion and exclusion criteria, 11 articles were selected for analysis. Results indicate that the articles indexed in Lillacs are predominantly descriptive, while those indexed in PsycINFO (APA) are mostly focused on the discussion of proposed intervention among families of guardian grandparents and grandchildren.
\end{abstract}

Keywords: grandparents, family, family relations, childrearing practices, child care

O aumento da população de idosos e da expectativa de vida do brasileiro (IBGE, 2010), o maior tempo de convivência entre gerações diferentes e as transformações nos arranjos familiares, entre outros fatores, compõem o cenário em que os avós têm assumido papéis de importância crescente nos relacionamentos familiares (Dias \& Costa, 2006; Dias, Costa, \& Rangel, 2005; Vitale, 2005). Diante desse contexto, o estudo das interações familiares, em especial das interações entre avós e netos, tem-se ampliado no Brasil nas últimas décadas (Dias \& Silva, 1999; Lopes, Neri \& Park, 2005).

As pesquisas realizadas no Brasil confirmam resultados de estudos conduzidos nos Estados Unidos (Fuller-Thomson, Minkler \& Driver, 1997; Glass \& Huneycutt, 2002), ao constatarem que os avós fornecem apoio instrumental e emocional à família em várias situações: separação/divórcio (Araújo \& Dias, 2002); gravidez na adolescência (Silva \& Salomão, 2003); pais com dificuldades para cuidar dos filhos por trabalharem fora, estarem desempregados, incapacitados ou despreparados (Falcão, Dias, Bucher-Maluscke, \& Salomão, 2006).

Atualmente, ampliou-se o número de lares em que se verifica a corresidência, nos quais várias gerações residem juntas, assim como aqueles em que os avós criam seus netos

1 Endereço para correspondência: UNICAP, Rua Almeida Cunha, 245, B1. G4, $8^{\circ}$ andar, Boa Vista, Recife, PE, Brasil. CEP. 50.050-480. E-mail:prof.teresafalcao@gmail.com integralmente. Nessa circunstância, eles são chamados "pais substitutos", "avós em tempo integral", "avós com custódia" (quando detêm a guarda dos netos judicialmente), "avós cuidadores" e também "avós guardiões" (Dias et al., 2005; Dias \& Costa, 2006; Lopes et al., 2005). Pode-se perceber que são diversas as situações que, entrelaçadas a uma multiplicidade de motivações, levam os avós a participar da vida dos netos assumindo papéis de relevância para a família e para a comunidade (Dias, Aguiar \& Hora, 2009).

O interesse pelo estudo dos avós guardiões iniciou-se na década de 90, pois, de acordo com Glass e Huneycutt (2002), somente a partir daí, nos Estados Unidos, pesquisadores, educadores e mídia em geral focalizaram o aumento crescente dessas famílias. Dias e Silva (1999), a partir de uma revisão de literatura, também situam na década de 90 o aumento do interesse em estudar os avós guardiões devido às necessidades de apoio aos avós e netos diante das dificuldades que enfrentam.

Inicialmente, os pesquisadores norte-americanos estudaram o perfil sociodemográfico dos avós guardiões e as situações que os levaram a criar os netos (Fuller-Thomson et al., 1997). Em pesquisas subsequentes, buscaram investigar o funcionamento psicossocial dos membros dessas famílias, as interações familiares, os comportamentos e as necessidades dos avós e dos netos (Glass \& Huneycutt, 2002). 
Os avós têm assumido o cuidado dos netos em tempo parcial ou integral e podem ser classificados, de acordo com Gerondo (2006), como cuidadores primários, quando assumem a criação integral dos netos, cuidadores secundários, quando cuidam devido a uma ausência temporária dos pais, e terciários, quando são chamados para ajudar em uma tarefa específica.

No caso dos avós guardiões, esse cuidado é em tempo integral e, por vezes, os avós têm a custódia dos netos, tornando-se seus cuidadores primários legais (Gerondo, 2006). Estudos revelam que, nessa situação, avós e netos enfrentam diversos desafios emocionais, sociais e financeiros (Dias \& Silva, 1999).

As relações entre avós e netos vão-se modificando à medida que os netos crescem (Oliveira \& Pinho, 2013). Isso implica acompanhar os vários aspectos da vida dos netos: social, emocional, cognitivo e moral. Na infância, isso significa lidar com a escola, considerada um importante contexto de desenvolvimento para essa faixa etária (Dessen \& Polonia, 2007).

Embora a relação avós e netos seja mais frequente no contexto familiar, a participação dos avós tem recentemente ocorrido também no contexto escolar. Segundo Cardoso (2010), os profissionais da escola têm constatado que os avós têm assumido o acompanhamento escolar dos netos. Dessa forma, a relação com a escola pode estar se constituindo um desafio importante que os avós enfrentam ao criarem seus netos, o que torna relevante questionar: como ocorre a relação entre os avós guardiões e a escola dos netos?

Este estudo se propõe realizar uma revisão sistemática de literatura com o objetivo de analisar artigos científicos sobre os avós que criam netos publicados no período dos últimos dez anos (2004/2014). Foram acessadas as bases de dados PsycINFO (APA), Lillacs e Scielo.

A análise realizada sobre os artigos poderá contribuir com pesquisadores e profissionais que trabalham com famílias de avós guardiões e seus netos. Espera-se, assim, favorecer a realização de novos estudos e a elaboração de estratégias de intervenção mais apropriadas às necessidades dessas famílias.

\section{Método}

A presente pesquisa de revisão sistemática de literatura foi realizada mediante uma busca eletrônica de artigos indexados nas bases eletrônicas de dados PsycINFO (APA), Lillacs e Scielo Regional.

Como descritores, foram pesquisadas na base de dados PsycINFO (APA) as palavras-chave presentes no resumo das publicações: grandparents AND grandchildren AND school. Na base Lillacs foram utilizadas as palavras: avós $A N D$ netos $A N D$ (escola $O R$ educação); abuelos $A N D$ nietos $A N D$ (escuela OR educación) para pesquisar o resumo dos artigos. $\mathrm{Na}$ base de dados Scielo Regional, foram pesquisadas, no resumo, as palavras em língua portuguesa e em língua espanhola: avós $A N D$ netos $A N D$ (escola $O R$ educação); abuelos AND nietos AND (escuela OR educación).

Foram incluídos, para fins de análise neste estudo, os artigos publicados nos últimos dez anos, ou seja, o período de janeiro de 2004 a julho de 2014. Além do período de publicação, foi estabelecido como critério de inclusão o acesso ao artigo completo de forma gratuita.

Foram definidos como critérios de exclusão: artigos duplicados, dissertações, capítulos de livro, artigos de revisão e artigos que não apresentassem em seu desenvolvimento uma análise sobre a temática dos avós que criam netos.

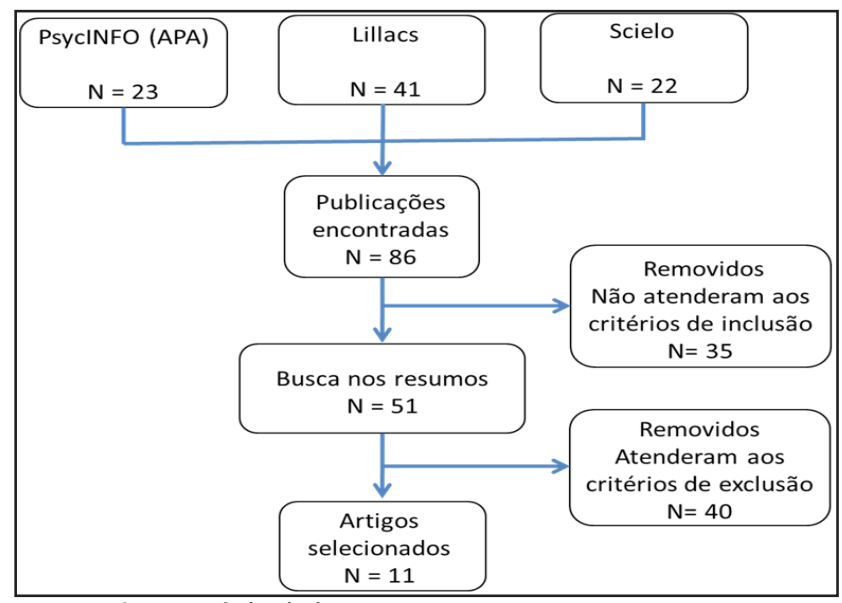

Figura 1. Estratégia de busca

A estratégia de busca dos artigos, descrita na Figura 1, foi realizada por dois juízes independentes. Na comparação dos resultados, em caso de divergência, buscou-se o consenso.

Foram encontradas na base PsycINFO (APA), 23 potencialmente relevantes. Considerando os critérios de inclusão, foram removidas 12 publicações: nove por estarem fora do período considerado e três por não terem acesso gratuito. Considerando os critérios de exclusão, foram removidas sete publicações: três dissertações, três capítulos de livro e uma publicação por não tratar da temática do estudo. Dessa forma, foram obtidos quatro artigos para análise.

$\mathrm{Na}$ base de dados Lillacs, para as palavras em língua portuguesa, foram encontradas 29 publicações, mas considerando os critérios de inclusão foram retiradas 11 publicações, das quais quatro não tinham acesso ao artigo completo e sete estavam fora do período considerado no estudo (2004/2014). Considerando os critérios de exclusão especificados, foram retirados duas teses, um artigo por ser revisão de literatura e oito publicações que não tratavam da temática dos avós que criam netos. Dessa forma, foram selecionados sete artigos para análise. Já para as palavras em língua espanhola, foram encontrados 12 artigos, cinco não atenderam aos critérios de inclusão por estarem fora do período considerado para o estudo (2004/2014), quatro foram excluídos por não abordarem a temática da pesquisa, dois foram excluídos, pois já haviam sido selecionados por apresentarem resumo na língua portuguesa e um por se tratar de revisão de literatura. Dessa forma, na base Lillacs foram selecionados ao total, sete artigos para análise.

$\mathrm{Na}$ base Scielo Regional foram encontrados, em língua portuguesa, 16 artigos publicados. Destes, seis não atenderam aos critérios de inclusão por não corresponderem ao período estabelecido para o estudo (2004/2014). Dez atenderam aos 
critérios de exclusão: oito por não abordarem a temática do estudo, um por ser duplicado e ter sido selecionado na base Lillacs e um por ser revisão de literatura. Na base Scielo Regional, em língua espanhola, foram encontradas seis publicações, uma não atendeu aos critérios de inclusão por estar fora do período (2004/2014) e cinco publicações foram excluídas por não abordarem a temática dos avós que criam netos. Sendo assim, nenhum artigo dessa base foi selecionado para análise.

Portanto, para esta revisão sistemática foram selecionadas 11 publicações ao todo, que foram lidas na íntegra. Foram analisadas com relação à autoria, ao ano de publicação, periódico, base de dados, participantes/público alvo, instrumentos/procedimentos, foco de análise, principais resultados e discussão.

Considerando os dados apresentados na Tabela 1, os artigos foram agrupados quanto ao foco de análise adotado.
Dessa forma, têm-se seis artigos descritivos, um artigo teórico e quatro artigos sobre estratégias de intervenção.

\section{Resultados}

Tendo em vista a contribuição dos estudos analisados nesta revisão, três temáticas foram destacadas como os principais resultados: situações que levam os avós a criar os netos; relacionamento entre os avós guardiões e os netos; relação entre os avós guardiões, os netos e a escola.

\section{Situações que Levam os Avós a Criar os Netos}

As razões que levaram os avós a assumirem a criação dos netos foram apresentadas na maioria dos estudos analisados nesta revisão. Identificar as razões pelas quais

Tabela 1. Características e resultados dos 11 artigos incluídos nesta revisão sistemática

\begin{tabular}{|c|c|c|c|c|c|}
\hline Autor (ano) & Objetivos & Participantes & Procedimentos & Foco & Resultados /Discussão \\
\hline Newsome \& Kelly (2004) & $\begin{array}{l}\text { Descrever um programa } \\
\text { baseado na Terapia Breve } \\
\text { Focal em grupo }\end{array}$ & Avós e netos & $\begin{array}{l}\text { Dinâmicas de grupo } \\
\text { realizadas no contexto } \\
\text { escolar }\end{array}$ & EI & $\begin{array}{l}\text { Sugere-se que as intervenções } \\
\text { sejam realizadas a partir da } \\
\text { perspectiva dos avós }\end{array}$ \\
\hline Edwards \& Daire, (2006) & $\begin{array}{l}\text { Descrever intervenções para } \\
\text { dar suporte aos avós e netos }\end{array}$ & Avós e netos & $\begin{array}{l}\text { Intervenções realizadas } \\
\text { na comunidade e no } \\
\text { contexto escolar }\end{array}$ & EI & $\begin{array}{l}\text { Avós ampliam seu papel } \\
\text { de criar netos. Habilidades } \\
\text { sociais e de aprendizagem são } \\
\text { desenvolvidas pelos netos }\end{array}$ \\
\hline Edwards \& Ray (2008). & $\begin{array}{l}\text { Fornecer aos profissionais } \\
\text { da escola um modelo de } \\
\text { intervenção junto às famílias } \\
\text { de avós que criam netos }\end{array}$ & $\begin{array}{l}\text { Avós, netos e } \\
\text { profissionais da } \\
\text { escola }\end{array}$ & $\begin{array}{l}\text { Intervenções } \\
\text { com estudantes. } \\
\text { Psicoeducação para } \\
\text { avós e profissionais da } \\
\text { escola }\end{array}$ & EI & $\begin{array}{l}\text { Estudantes melhoram sua } \\
\text { qualidade de vida. Professores } \\
\text { desenvolvem habilidades para } \\
\text { trabalhar com famílias de avós } \\
\text { que criam netos }\end{array}$ \\
\hline Gibson \& Mc-Glynn, (2013) & $\begin{array}{l}\text { Explorar as estratégias } \\
\text { utilizadas pelas avós que } \\
\text { criam netos }\end{array}$ & 10 avós & Entrevistas & EI & $\begin{array}{l}\text { Educadores necessitam ampliar } \\
\text { seus conhecimentos sobre as } \\
\text { famílias dos avós e netos }\end{array}$ \\
\hline Klein, (2009) & $\begin{array}{l}\text { Estudar a relação entre avós } \\
\text { e netos adolescentes }\end{array}$ & - & - & ET & $\begin{array}{l}\text { Avós passaram a cuidar e criar } \\
\text { seus netos devido às mudanças } \\
\text { sociais e familiares }\end{array}$ \\
\hline Araújo \& Dias (2010) & $\begin{array}{l}\text { Investigar as vivências e } \\
\text { percepções de avós que } \\
\text { criam os netos }\end{array}$ & $\begin{array}{l}\text { Nove avós e } \\
\text { um avô }\end{array}$ & Entrevistas & ED & $\begin{array}{l}\text { Os principais motivos para os } \\
\text { avós criarem os netos foram a } \\
\text { gravidez na adolescência e a } \\
\text { separação dos pais }\end{array}$ \\
\hline Dias, Hora \& Aguiar (2010) & $\begin{array}{l}\text { Investigar como os jovens } \\
\text { criados por avós e pais } \\
\text { vivenciam tal situação }\end{array}$ & $\begin{array}{l}43 \text { netas e } 35 \\
\text { netos, com } \\
\text { média de idade } \\
\text { de } 16 \text { anos }\end{array}$ & Questionário & $\mathrm{ED}$ & $\begin{array}{l}\text { O comportamento dos } \\
\text { cuidadores e a disponibilidade } \\
\text { de tempo são aspectos } \\
\text { diferenciais entre pais e avós }\end{array}$ \\
\hline $\begin{array}{l}\text { Oliveira, Vianna \& Cárdenas } \\
\text { (2010) }\end{array}$ & $\begin{array}{l}\text { Avaliar a relação entre avós e } \\
\text { netos no período da infância }\end{array}$ & $\begin{array}{l}17 \text { avós e oito } \\
\text { netos }(37 \% \\
\text { residiam com } \\
\text { a avó) }\end{array}$ & Entrevistas & $\mathrm{ED}$ & $\begin{array}{l}\text { As avós possuíam intenso } \\
\text { vínculo com os netos, o que é } \\
\text { reconhecido por eles }\end{array}$ \\
\hline $\begin{array}{l}\text { Paula, Silva, Bessa, Morais \& } \\
\text { Marques (2011) }\end{array}$ & $\begin{array}{l}\text { Identificar as mudanças das } \\
\text { relações intergeracionais } \\
\text { percebidas pelo idoso }\end{array}$ & $\begin{array}{l}11 \text { avós e um } \\
\text { avô }\end{array}$ & Entrevistas & $\mathrm{ED}$ & $\begin{array}{l}\text { Para os idosos, a autoridade, } \\
\text { antes existente, deu lugar a } \\
\text { conflitos e à falta de respeito }\end{array}$ \\
\hline Cardoso \& Costa (2012) & $\begin{array}{l}\text { Analisar as relações } \\
\text { familiares quando avós } \\
\text { requerem a guarda judicial } \\
\text { dos netos }\end{array}$ & $\begin{array}{l}\text { Seis famílias } \\
\text { em avaliação } \\
\text { psicossocial }\end{array}$ & Entrevistas & ED & $\begin{array}{l}\text { A guarda de netos pode se } \\
\text { constituir em um desafio de } \\
\text { adaptação para o idoso }\end{array}$ \\
\hline $\begin{array}{l}\text { Mainetti \& Wander-broocke } \\
\text { (2013) }\end{array}$ & $\begin{array}{l}\text { Investigar as mudanças na } \\
\text { vida das avós decorrentes da } \\
\text { criação dos netos }\end{array}$ & 10 avós & Entrevistas & $\mathrm{ED}$ & $\begin{array}{l}\text { O papel de mãe dos netos } \\
\text { sobrepõe-se ao papel de avó }\end{array}$ \\
\hline
\end{tabular}

Nota: EI = Estratégias de Intervenção; ET = Estudo Teórico; ED = Estudo Descritivo. 
os avós passaram a criar os netos torna-se importante, principalmente pelas possíveis repercussões dessas razões no bem-estar psicológico dos avós, dos netos e na qualidade do relacionamento entre eles.

O estudo de Edwards e Ray (2008) apresenta uma síntese das razões que levam os avós a criar os netos, destacando que vários estudos apontam quatro razões como as mais citadas, sendo chamadas pelos pesquisadores como four D's (quatro D's), a saber, "divorce, desertion, drugs and death". Ou seja, divórcio, abandono, drogas e morte. Assim, para os autores citados, os avós assumem a criação dos netos diante de situações de crise e perda na família.

Araújo e Dias (2010) ampliam o foco e descrevem várias situações que envolvem mudanças na família e motivam os avós a assumir a criação dos netos, tais como gravidez na adolescência; trabalho em horário integral ou desemprego dos pais; recasamento de pais separados e não aceitação da criança por parte do novo cônjuge, entre outras situações. Mainnert e Wanderbroocke (2013) alertam também que, em muitos casos, ocorre uma sobreposição de motivos, assim como, em geral, os avós assumem a criação dos netos por participarem anteriormente dos seus cuidados, coabitarem ou morarem próximos aos netos.

O estudo de Costa e Carvalho (2012) analisa os motivos que levaram os avós a acessarem a Justiça para obter a guarda dos netos. Situações de abandono dos netos, negligência, morte, doença mental e uso de drogas pelos genitores foram relatadas pelas famílias entrevistadas. Os avós pesquisados já eram os principais provedores financeiros dos netos, contando com a aposentadoria para tal. No entanto, preocupados com o que poderia ocorrer aos netos, buscavam assumir todo o cuidado deles.

Embora as pesquisas indiquem que eventos traumáticos estejam por trás das razões que levam os avós a criar os netos, segundo Newsome e Kelly (2004), as adversidades podem ser vistas pelos avós como uma segunda chance para serem pais novamente e acertar, principalmente quando criam netos cujos pais estão envolvidos com drogas, encarcerados ou com doença mental. Edwards e Daire (2006) apontam que a experiência de criar netos pode ser benéfica para avós e netos. Segundo os autores citados, os avós reconhecem que são necessários para os netos, que, por sua vez, fornecemlhes um propósito de vida. Os autores consideram também que viver com quem se ama e se dispõe a criá-lo(la) pode ser percebido pelo(a) neto(a) como uma oportunidade de manter a conexão com sua família e história.

\section{Relacionamento entre os Avós Guardiões e Netos}

Além de identificar as razões que levaram os avós a criar os netos, percebeu-se uma preocupação presente na maioria dos artigos analisados quanto às repercussões dessa configuração familiar no relacionamento estabelecido entre os avós guardiões e os netos. Nos estudos de Araújo e Dias (2010) e Oliveira, Vianna e Cárdenas (2010), os avós entrevistados relataram manter um forte vínculo afetivo com os netos, expresso através dos sentimentos de satisfação e felicidade. Contudo, os avós reconheceram dificuldades relacionadas ao aumento das despesas e tarefas domésticas, assim como em colocar limites na educação dos netos, especialmente quando eles se aproximam da adolescência (Mainnert \& Wanderbroocke, 2013; Oliveira et al., 2010).

Os artigos analisados confirmam os resultados de outras pesquisas sobre essa temática, nas quais os avós referiram sentimentos ambivalentes por criar os netos, atravessados por fatores como sexo e idade dos avós, saúde, condições socioeconômicas, relacionamento com filhos, genros/noras (Dias, Costa, \& Rangel, 2005). Nessa situação, os avós podem estar sujeitos a desenvolver problemas funcionais e de saúde (Dias \& Costa, 2006).

Ao comparar o relacionamento entre avós e netos em gerações diferentes, os idosos entrevistados por Paula, Silva, Bessa, Morais e Marques (2011) relataram que a convivência com os netos envolve respeito e afeto, mas a autoridade, antes baseada no medo, deu lugar, atualmente, à presença de conflitos e, para alguns, falta de respeito. Os avós atribuem isso à "educação moderna" dada pelos pais, bem como ao fato de darem muita liberdade para os netos. Tais fatores são percebidos pelos avós como uma motivação importante para a falta de respeito por parte dos netos e para a mudança nos relacionamentos familiares.

Klein (2009), ao revisar vários estudos, propõe que não existe uma só tendência para os relacionamentos entre avós e netos adolescentes. Na sua pesquisa, o autor menciona diferentes formas de vínculo, classificando-o em tradicionais, não tradicionais e inédito. Nos primeiros, os avós são vistos como aqueles que cuidam a partir do altruísmo e do autossacrifício, tentando compensar, muitas vezes, a falta de cuidado dos pais. Vínculos não tradicionais surgem quando se estabelece uma relação simétrica, construída nas atividades cotidianas. Avós e netos necessitam um do outro e desenvolvem um vínculo de apego seguro que tem a ver com cooperação e solidariedade intergeracional. Nas formas de vínculo inéditas, ainda não muito estudadas, ocorre um processo de confrontação dos netos com seus avós e destes com seu papel de avós, o que resulta em conflito, raiva, ressentimento e acusações mútuas.

Os netos entrevistados nos estudos de Oliveira et al. (2010) e de Dias, Hora e Aguiar (2010), vivendo momentos diferentes do desenvolvimento, na infância e juventude respectivamente, revelaram forte vínculo afetivo e demonstraram sentimentos de satisfação no relacionamento com os avós. Tais pesquisas confirmam os resultados de vários estudos que destacam a importância emocional da presença dos avós na vida dos netos (Azambuja \& Rabinovich, 2013; Lopes et al., 2005; Kipper \& Lopes, 2006; Oliveira \& Pinho, 2013). Entre as repercussões na vida dos avós e dos netos, Mainnert e Wanderbroocke (2013) sugerem a realização de novas pesquisas que explorem os impactos na vida conjugal e social dos avós que passaram a criar netos, assim como as implicações dessa criação na vida dos netos adultos.

\section{Relação entre os Avós Guardiões, os Netos e a Escola}

Embora as pesquisas sobre avós que criam netos tenham aumentado, de acordo com Edwards e Ray (2008), a literatura sobre o desenvolvimento psicossocial das crianças nessa configuração familiar ainda não integrou os dados das poucas 
pesquisas sobre o funcionamento escolar dessas crianças. Além disso, segundo os autores, as pesquisas sobre crianças criadas exclusivamente pelos avós apresentam resultados conflitantes: enquanto algumas referiram que os netos apresentavam funcionamento semelhante aos seus pares na escola e no ambiente social, outras encontraram um maior grau de doenças, hiperatividade e problemas socioemocionais na escola.

Edwards e Ray (2008) pontuam que crianças criadas por seus avós são consideradas de alto risco, podendo vir a desenvolver problemas na escola e não alcançar bons resultados ao longo da vida devido aos eventos traumáticos que motivaram o surgimento dessa configuração familiar. Os avós, por sua vez, também podem ter dificuldades para oferecer apoio à vida escolar dos netos por várias razões, entre elas, idade avançada, saúde debilitada e falta de habilidade e de conhecimentos para orientar as tarefas de casa dos netos. Entretanto, os autores salientam que nem sempre isso ocorre, pois fatores como idade, nível educacional, condições financeiras, apoio social e outras variáveis podem influenciar o resultado obtido por avós e netos.

Para atenuar as dificuldades e o estresse envolvidos na situação de criar os netos, Edwards e Daire (2006) sugerem que avós e netos sejam estimulados a desenvolver uma rede de apoio social em sua comunidade, incluindo a escola e a igreja. Os autores constataram que, quando os avós recebem suporte emocional e instrumental de outros significativos, eles melhoram seu bem-estar físico e emocional, o que favorece a relação com a escola dos netos. Os artigos indexados na PsycINFO (APA) analisados nesta revisão destacam a importância de os profissionais da escola (psicólogos, conselheiros e outros) desenvolverem trabalhos no contexto escolar com as famílias de avós que criam netos.

Edwards e Ray (2008) apresentam várias estratégias de prevenção e intervenção a serem utilizadas pelo psicólogo escolar junto aos avós, netos, professores e demais profissionais da escola. Os psicólogos escolares podem oferecer, para as crianças, aconselhamento individual ou em grupo, para trabalhar com foco nos sentimentos de perda, rejeição e abandono; gestão de raiva e estresse; melhora da autoestima, entre outros aspectos. Eles também podem implementar treinamento de habilidades comportamentais para auxiliar os netos a fazer e manter amizades e também para desenvolver estratégias de estudo.

Para os avós, os autores sugerem que os psicólogos escolares ofereçam: psicoeducação para elaboração de competências parentais (Edwards e Ray, 2008); atividades em grupo realizadas a partir da Terapia Breve Focal (Newsome \& Kelly, 2004); além de orientação para serviços de referência realizados fora da escola para aconselhamento intergeracional, intervenções nas interações, suporte emocional e assistência financeira, quando necessária (Edwards \& Daire, 2006; Edwards \& Ray, 2008).

As escolas, segundo Edwards e Daire (2006), constituemse no centro da maioria das comunidades e são importantes recursos para ajudar a gerenciar as necessidades de crianças criadas pelos avós. Para que a escola realize essa mediação, Edwards e Ray (2008) destacam que é importante que o psicólogo escolar realize psicoeducação e treinamentos com os professores e demais profissionais da escola para sensibilizá-los quanto às dificuldades enfrentadas pelos avós e os netos, assim como para favorecer o trabalho com essas famílias. Sugerem também que as escolas ofereçam tutoria e apoio de pares para que os netos aprendam a lidar com dificuldades acadêmicas (Edwards \& Daire, 2006).

Newsome e Kelly (2004) apresentam um programa de atividades em grupo com avós e destacam que as intervenções sejam pensadas considerando a perspectiva dos avós e que eles tenham um papel ativo, assumindo inclusive a condução dos encontros. Na relação com os professores, Edwards e Daire (2006) recomendam que os avós se aliem e se coloquem como recursos de suporte e assistência aos netos. Na mesma direção, Gibson e McGlynn, (2013) relatam que avós que desenvolveram estratégias para apoiar os netos diante de suspensões escolares, também assumiram uma postura ativa ao fornecer recomendações aos professores, o que pode ajudar a ampliar a compreensão das causas das suspensões.

\section{Discussão}

Este artigo teve como objetivo apresentar uma revisão sistemática da literatura científica acerca dos avós que criam netos. Constatou-se que, embora os estudos sobre as relações entre avós e netos tenham aumentado nas últimas décadas, os resultados encontrados nesta revisão apontam que as pesquisas sobre os avós guardiões são mais recentes e ainda escassas, sobretudo quando se investiga a relação desses avós com outros contextos de desenvolvimento, tal como a escola dos netos.

Constatou-se que os artigos indexados na base Lillacs são predominantemente descritivos com foco nas relações intergeracionais. Os indexados na PsycINFO (APA) são voltados para a discussão de estratégias de intervenção realizadas por psicólogos no contexto escolar norteamericano junto às famílias dos avós guardiões e seus netos.

Todos os artigos indexados na base Lillacs apresentam dados obtidos a partir de entrevistas realizadas com as avós, mais especificamente com as avós maternas. Poucos estudos obtiveram a participação do avô nas entrevistas. É possível que essa diferença, quanto aos participantes dos estudos, revelem aspectos do processo de envelhecimento populacional atrelados às questões socioeconômicas e culturais que repercutem no papel que as avós maternas têm assumido na família. Diante desse quadro, discute-se a importância de estudos futuros que focalizem o papel do avô e investiguem a possível diferença entre o papel da avó e do avô em relação à criação de netos.

As vivências e as percepções de netos criados por avós, na infância e adolescência, também foram consideradas nos estudos publicados. No entanto, considera-se importante a ampliação das investigações para focalizar o relacionamento intergeracional de netos adultos e seus avós, na tentativa de conhecer as repercussões desses relacionamentos para ambos, tendo em vista a importância da compreensão do desenvolvimento da solidariedade intergeracional, tema ainda pouco explorado e tão importante diante dos processos de envelhecimento populacional.

$\mathrm{O}$ acesso à justiça para a obtenção da guarda judicial dos netos e os conflitos vivenciados nas famílias, diante 
dessa situação, foi abordado em um dos estudos analisados. A complexidade dos conflitos e das tramas relacionais familiares antecede a decisão judicial e, em muitos casos, tais conflitos podem ter continuidade após a sentença, o que torna relevante a realização de estudos que possam investigar essas mudanças na configuração familiar ao longo do tempo.

Pode-se considerar, então, que a principal contribuição desta revisão foi apresentar e analisar os estudos que, no período dos últimos dez anos, focalizaram as relações entre avós guardiões e seus netos. Além dessa contribuição mais geral, destaca-se também como uma importante contribuição, a discussão de um conjunto de estratégias de prevenção e intervenção realizadas por psicólogos no contexto escolar norte-americano apresentadas nos estudos analisados que estão indexados na base PsycINFO (APA). Importante destacar que tais estratégias de intervenção têm como público alvo os avós guardiões, os netos e os profissionais da escola (funcionários e professores), o que revela a importância de uma abordagem sistêmica, que possibilite a consideração de todos os envolvidos na relação, nesse caso, os avós, os netos e os profissionais da escola.

No Brasil, Nunes e Vilarinho (2001) desenvolveram um projeto de intervenção na escola junto aos avós das crianças do ensino fundamental com o objetivo de favorecer uma maior integração escola-família. Os avós participaram de encontros na escola e colaboraram trazendo ideias para o desenvolvimento do trabalho pedagógico. Nesse projeto, a maioria dos avós que participaram morava em suas próprias residências e apenas uma bisavó criava o bisneto sem a ajuda dos pais. Embora não se trate de uma intervenção com avós guardiões, o referido estudo se assemelha aos que foram analisados anteriormente, por ter sido realizado no contexto escolar e por contar com a participação ativa dos avós nas atividades.

Ao realizar um estudo exploratório com avós, estudantes e professores de duas escolas públicas na Ilha de São Miguel Açores (Portugal), Silva (2012) destacou a colaboração dos avós que, por vezes, assumem o papel de educar os netos, contribuindo com seu desempenho escolar e estando presentes na escola dos mesmos. Os professores entrevistados ressaltaram que nas atividades em que os pais podem acompanhar os filhos, raramente o fazem, enquanto os avós participam das atividades e estão sempre presentes.

Entre os estudos sobre avós guardiões realizados no Brasil, Coutrim, Boroto, Vieira e Maia (2007) investigaram a influência dos avós no desempenho escolar dos netos. Os resultados apontaram que os avós procuram garantir que tudo esteja em ordem na vida familiar e escolar dos netos, havendo casos em que mesmo com baixa escolaridade e com dificuldades de auxiliar diretamente nas tarefas escolares, valorizam a educação e providenciam ajuda para os netos junto aos parentes e vizinhos.

A partir dessa revisão, percebe-se, na última década, uma lacuna de artigos que explorem as relações entre os avós guardiões e o contexto escolar dos netos na realidade brasileira. Alguns estudos apresentam um foco ampliado por tratar de questões educacionais, e, como colocado anteriormente, considerar os avós de maneira geral, sem destacar a situação dos avós guardiões. Nessa direção, alguns pesquisadores investigaram processos coeducativos entre avós e netos (Oliveira, 2009; Oliveira, 1998; Schmidt, 2007), outros abordaram como os avós avaliam a educação dos netos, especialmente as práticas parentais de educação (Sarat, 2007; Silva, 2010). Sendo assim, considera-se importante a realização de pesquisas sobre a temática da relação entre os avós guardiões e contexto escolar brasileiro, as quais, por sua vez, poderiam subsidiar o desenvolvimento de estratégias de intervenção junto a essas famílias na escola.

\section{Referências $^{1}$}

Araújo, M. R. G. L., \& Dias, C. M. de S. B. (2002). Papel dos avós: Apoio oferecido aos netos antes e após situações de separação/ divórcio dos pais. Estudos de Psicologia, 7(1), 91-101.

*Araújo, C. P., \& Dias, C. M. de S. B. (2010). Avós guardiões de baixa renda. Pesquisas e Práticas Psicossociais, 4(2), 229-237.

Azambuja, R. M. M., \& Rabinovich, E. P. (2013). Relações intergeracionais: Concepções de netos sobre avós cuidadores. Apresentado no II CONINTER - Congresso Internacional Interdisciplinar em Sociais e Humanidades, Belo Horizonte, MG, Brasil.

Cardoso, A. R. (2010). Ser avó para "estragar" ou para "educar”? Um estudo com grupos de avós que cuidam de netos (Tese de Doutorado). Universidade do Estado do Rio de Janeiro, Rio de Janeiro. Retirado de http://www.bdtd.uerj.br/tde_busca/ arquivo.php?codArquivo=

*Cardoso, V. S., \& Costa, L. F. (2012). Guarda judicial de netos: Tempo e dinheiro nas interações familiares. Aletheia, 38-39, 109-123.

Coutrim, R. M. da E., Boroto, I. G., Vieira, L. C., \& Maia, I. de O. (2007). O que os avós ensinam aos netos? A influência da relação intergeracional na educação formal e informal. Comunicação oral apresentada no XIII Congresso Brasileiro de Sociologia, Universidade Federal de Pernambuco, Recife, Pernambuco, Brasil.

Dessen, M. A., \& Polonia, A. da C. (2007). A família e a escola como contextos de desenvolvimento humano. Paidéia, 17(36), 21-32.

Dias, C. M. de S. B., \& Silva, D. V. (1999). Os avós: Uma revisão da literatura nas três últimas décadas. In T. Féres-Carneiro (Org.), Casal e família: Entre a tradição e a transformação (pp. 118-149). Rio de Janeiro: Editora Nau.

Dias, C. M. de S. B., Costa, J. M., \& Rangel, V. A. (2005). Avós que criam seus netos: Circunstâncias e conseqüências. In T. FéresCarneiro (Org.), Família e casal, efeitos da contemporaneidade (pp. 158-176). Rio de Janeiro: PUC-Rio.

Dias, C. M. de S. B., \& Costa, J. M. (2006). Um estudo sobre a avó guardiã na cidade do Recife. In M. C. L. de A. Amazonas, A. de O. Lima, \& C. M. de S. B. Dias (Orgs.), Mulher e família: Diversos dizeres (pp. 127-138). São Paulo: Oficina do Livro Editora.

Dias, C. M. de S. B., Aguiar, A. G. de S. \& Hora, F. F A. (2009). Netos criados por avós: Motivos e repercussões. In T. FéresCarneiro (Org.), Casal e família: Permanências e rupturas (pp. 41-58). São Paulo: Casa do Psicólogo.

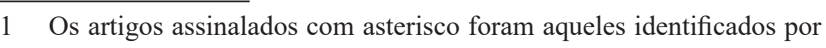
meio da revisão sistemática. 
*Dias, C. M. de S. B., Hora, F. F. A. da, \& Aguiar, A. G. de S. (2010). Jovens criados por avós e por um ou ambos os pais. Psicologia: Teoria e Prática, 12(2), 188-199.

*Edwards, O. W., \& Daire, A. P. (2006). School-age children raised by their grandparents: Problems and solutions. Journal of Instructional Psychology, 33(2), 113-119.

*Edwards, O., \& Ray, S. (2008). An attachment and school satisfaction framework for helping children raised by grandparents. School Psychology Quarterly, 23(1), 125-138. doi:10.1037/1045-3830.23.1.125

Falcão, D. V. da S., Dias, C. M. de S. B., Bucher-Maluscke, J. S. N. F., \& Salomão, N. M. R. (2006). As relações familiares entre as gerações: possibilidades e desafios. In D. V. da S. da Silva Falcão \& C. M. de S. B. Dias (Orgs.), Maturidade e velhice: Pesquisas e intervenções psicológicas (pp. 59-80). São Paulo: Casa do Psicólogo.

Fuller-Thomson, E., Minkler, M., \& Driver, D. (1997). A profile of grandparents raising grandchildren in the United States. The Gerontologist, 37, 406-411.

Gerondo, V. (2006). As avós idosas cuidadoras dos netos hospitalizados (Dissertação de Mestrado). Universidade Federal do Paraná, Curitiba. Retirado de http://www.ppgenf. ufpr.br/Disserta\%C3\%A7\%C3\%A3oVanessaGerondo.PDF

*Gibson, P. A., \& McGlynn, C. (2013). Enough is enough: Grandmother caregivers' strategies for mitigating out-ofschool suspensions for African-American youth. Children and Youth Services Review, 35(11), 1836-1842. doi:10.1016/j. childyouth.2013.08.004

Glass, J. C., \& Huneycutt, T. L. (2002). Grandparents parenting grandchildren: Extent of situation, issues involved, and educational implications. Educational Gerontology, 28: $139-161$.

IBGE. (2010). Primeiros resultados definitivos do Censo 2010: População do Brasil é de 190.755.799 pessoas. Retirado de http://saladeimprensa.ibge.gov.br/noticias?view=noticia\&id= $1 \&$ busca $=1 \&$ idnoticia $=1866$

Kipper, C. D. R., \& Lopes, R. S. (2006). O tornar-se avó no processo de individuação. Psicologia: Teoria e Pesquisa, 22(1), 29-34. http://dx.doi.org/10.1590/S0102-37722006000100004.

*Klein, A. (2009). Una aproximación a las formas de relacionamiento abuelos-nietos adolescentes desde perspectivas tradicionales, no tradicionales e inéditas. Psicologia Revista, 18(1). Retirado de http://revistas.pucsp.br/index.php/psicorevista/article/ view/3311

Lopes, E. S. de L., Neri, A. L., \& Park, M. B. (2005). Ser avós ou ser pais: Os papéis dos avós na sociedade contemporânea. Textos sobre Envelhecimento, 8(2), 239-253.

*Mainetti, A. C., \& Wanderbroocke, A. C. N. S. (2013). Avós que assumem a criação de netos. Pensando Famílias, 17(1), 87-98.
*Newsome, W. S., \& Kelly, M. (2004). Grandparents raising grandchildren: A solution-Focused Brief Therapy approach in school settings. Social Work with Groups, 27(4), 65-84. doi:10.1300/J009v27n04_06

Nunes, D. G., \& Vilarinho, L. R. G. (2001). "Família possível” na relação escola-comunidade. Psicologia Escolar e Educacional, 5(2), 21-29.

Oliveira, N. H. D. (2009). Recomeçar: Familia, filhos e desafios [online]. São Paulo: Editora UNESP. Retirado de http://www. cairu.br/biblioteca/arquivos/Psicologia/Recomecar.pdf

Oliveira, P. de S. (1998). Cultura e co-educação de gerações. Psicologia USP, 9(2). doi:http://dx.doi.org/10.1590/S010365641998000200011

Oliveira, A. R. V., \& Pinho, D. L. M. (2013). Relationships between grandparents and their teenage grandchildren: An integrative review. Revista Brasileira de Geriatria e Gerontologia, 16(3), 633-642.

*Oliveira, A. R. V., Vianna, L. G., \& Cárdenas, C. J. (2010). Avosidade: Visões de avós e de seus netos no período da infância. Revista Brasileira de Geriatria e Gerontologia, 13(3), 461-467.

*Paula, F. V. de, Silva, M. J. da, Bessa, M. E. P., Morais, G. L. A. de, \& Marques, M. B. (2011). Avós e netos no século XXI: Autoridade, afeto e medo. Revista da Rede de Enfermagem do Nordeste, 12(número especial). Retirado de http://www. revistarene.ufc.br/revista/index.php/revista/article/view/311

Sarat, M. (2007). Avós e netos: As relações estabelecidas nos processos educativos e civilizadores. Comunicação oral apresentada no X Simpósio Internacional Processo Civilizador, Campinas, SP. Retirado de http://www.uel.br/grupo-estudo/ processoscivilizadores/portugues/sitesanais/anais10/Artigos_ PDF/Magda_Sarat.pdf

Schmidt, C. (2007). As relações entre avós e netos: Possibilidades coeducativas? (Dissertação de Mestrado). Universidade Federal do Rio Grande do Sul, Porto Alegre. Retirado de http://www. lume.ufrgs.br/bitstream/handle/10183/13741/000617681. pdf? sequence $=1 \&$ locale $=$ pt_BR

Silva, A. M. (2012). A colaboração dos avós na educação dos netos. Interfaces Científicas-Educação, 1(1), 67-75.

Silva, A. P. G. (2010). Percepções de avós cuidadoras maternas sobre a criação e educação dos netos (Dissertação de Mestrado). Universidade Federal de Juiz de Fora, Juiz de Fora. Retirado de http://www.ufjf.br/ppgpsicologia/files/2010/01/ Anna-Paula-Gomes-da-Silva.pdf

Silva, D. V., \& Salomão, N. M. R. (2003). A maternidade na perspectiva de mães adolescentes e avós maternas dos bebês. Estudos de Psicologia, 8(1), 135-145.

Vitale, M. A. F. (2005). Avós: Velhas e novas figuras da família contemporânea. In Acosta, A. R., \& Vitale, M. A. F., Família: redes, laços e políticas públicas (2nd ed., pp. 93-105). São Paulo: Cortez. 